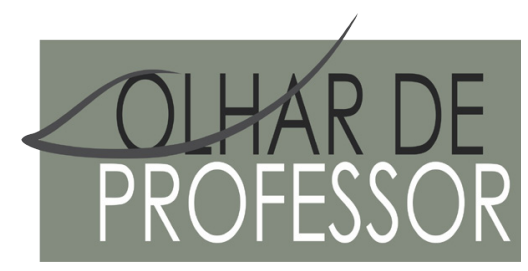

DOI: 10.5212/OLHARPROFR.v.22.0021

\title{
DE JOGADOR A DESENVOLVEDOR: A CRIAÇÃO DE JOGOS NO ROMPIMENTO DAS BARREIRAS EDUCACIONAIS ENCONTRADAS POR CRIANÇA COM TRANSTORNO DE DÉFICIT DE ATENÇÃO E HIPERATIVIDADE
}

\author{
FROM PLAYER TO DEVELOPER: THE CREATION OF GAMES OVER THE EDUCATIONAL BARRIERS BROKEN BY \\ CHILDREN WITH ATTENTION DEFICIT HYPERACTIVITY DISORDER
}

\section{DE JUGADOR A DESARROLLADOR: LA CREACIÓN DE JUEGOS EN EL ROMPIMIENTO DE LAS BARRERAS EDUCACIONALES ENCONTRADAS POR NIÑOS CON DÉFICIT DE ATENCIÓN CON HIPERACTIVIDAD}

\author{
LUCIANA DE LIMA* \\ DANIELLE GONZAGA DA SILVA* \\ ALESSANDRA DE MELO FERREIRA*** \\ FRANCISCO DANRLEY NASCIMENTO ALVES
}

\begin{abstract}
Resumo: O presente trabalho tem como objetivo descrever o processo de elaboração de livro-jogo por aluno com Transtorno de Déficit de Atenção e Hiperatividade (TDAH) ao estudar conceitos históricos. Em um cenário de imersão digital, considera-se importante a utilização de tais recursos em contexto escolar para o rompimento das possíveis barreiras educacionais, além da ruptura da estrutura hierárquica e das relações de poder encontradas no sistema educacional. Para isso, desenvolveu-se um Estudo de Caso com uma criança de oito anos, estudante de escola particular com diagnóstico médico de TDAH. Os dados foram coletados nos meses de abril a junho de 2019, através de atividades de sondagem e da elaboração de um livro-jogo dentro do software Twine. Percebeu-se que os obstáculos encontrados pela criança na realização de atividades em sala de aula regular foram transpostos ao utilizar a programação do livro-jogo.
\end{abstract}

Palavras-chave: Transtorno de Déficit de Atenção e Hiperatividade, Twine, Livro-jogo, Tecnologia Digital.

\begin{abstract}
The following article has a goal to describe the process of elaboration of a book-game by a student with Attention Deficit Hyperactivity Disorder to study historical concepts. In a scenario of digital immersion, it is rather important the use of these resources in the scholar context for breaking of possible structural barriers in the educational system, beyond the rupture of the hierarchical structure and power relationships found in the educational system. For that, was developed a Study of Case with an eight-year-old child medically diagnosed with ADHD. The data were collected between April, May, and June of 2019, through a polling and the elaboration of a book-game inside the software Twine with a content chosen by the student. It was noticed that the obstacles found by the child during the realization of the activities at a regular class were transposed with the use of the book-game.

Keywords: Attention Deficit Hyperactivity Disorder, Twine, Book-game, Digital Technology.

\footnotetext{
*Professora Adjunta da Universidade Federal do Ceará, com lotação no Instituto Universidade Virtual (IUVI). E-mail: proluli@ gmail.com

${ }^{* *}$ Graduanda em Pedagogia. Universidade Federal do Ceará. E-mail: daniellegonzaga9@gmail.com

*** Graduanda em Letras. Universidade Federal do Ceará. E-mail: ferreira.alessandra.melo@gmail.com

**** Graduando em Pedagogia. Universidade Federal do Ceará. E-mail: fcodan15@gmail.com
} 
Resumen: El presente trabajo tiene como objetivo describir el proceso de elaboración de un libro-juego, para el estudio conceptos históricos, para un alumno con Trastorno por Déficit de Atención con Hiperactividad. En un contexto de inmersión digital, es considerado importante el uso de tales recursos en contexto escolar para romper barreras educacionales, así como la ruptura de la estructura jerárquica y de las relaciones de poder del sistema educacional. Para estudiar esto, se desarrolló un estudio de caso con un niño de ocho años, estudiante de escuela privada con diagnóstico de TDAH. Los datos se recolectaron durante los meses de abril, mayo y junio de 2019, a través de encuestas y de la elaboración de un libro-juego utilizando el software Twine con una temática elegida por el estudiante. Se percibió que las barreras halladas por el niño en el transcurso de las actividades en el aula regular, fueron traspasadas con éxito durante el uso del libro-juego.

Palabras claves: Trastorno por Déficit de Atención con Hiperactividad. Twine. Libro-juego. Tecnologías Digitales.

\section{INTRODUÇÃO}

De acordo com os princípios estabelecidos pela Constituição da República Federativa do Brasil (BRASIL, 1988), a educação é um direito de todos e dever do Estado, alterando os moldes de uma escola excludente. Essa história de exclusão evidenciou a necessidade de refletir acerca do papel da escola e de suas ações direcionadas à inserção, garantia de permanência e efetivação da aprendizagem para todas as crianças.

A problemática que impulsionou esta investigação gira em torno do Transtorno de Déficit de Atenção e Hiperatividade (TDAH) e o desenvolvimento de estratégias didáticas que respeitem suas especificidades, considerando que sujeitos que apresentam essa característica, manifestam atividade global desorganizada, impulsividade, ausência de continuidade das atividades realizadas, entre outros fatores que podem variar de acordo com seu subtipo.

Conforme destacam Maia e Confortin (2015), é comum identificar no âmbito educacional professores alheios a questões referentes à inclusão desse grupo no ensino regular, por vezes julgando como indisciplina ou falta da imposição de regras. Isto é alarmante, visto que a instituição escolar é parte essencial na construção de conhecimentos referentes à leitura e à escrita, atividades que demandam concentração e uma abordagem diferenciada.

Diante desse contexto de poucos estudos aprofundados, de escassa formação ou experiências que embasam uma prática inclusiva, considera-se que o uso das Tecnologias Digitais da Informação e Comunicação (TDICs) dinamiza o processo de aprendizagem, contemplando as demandas educacionais daqueles que possuem TDAH.

É possível notar que as constantes transformações que a sociedade tem apresentado, impactam diretamente as relações sociais e, com isso, a correlação entre sistema educacional e os sujeitos que estão nele inseridos. Documentos norteadores, como a Base Nacional Comum Curricular (BNCC), já reconhecem tal fato ao afirmar a importância dos conhecimentos historicamente construídos sobre "o mundo físico, social, cultural e digital para entender e explicar a realidade” (BRASIL, 2017, p. 9). Considerando-se esse aspecto como relevante para o estudo, Tourinho, Bonfim e Alves (2016), afirmam a importância dos jogos digitais para o estímulo das Funções Executivas, além de compreenderem que “os jovens apresentam melhores performances nos games com os quais interagem, realizando transposições para ambientes out game e tarefas realizadas no dia a dia” (TOURINHO; BONFIM; ALVES, 2016, p. 876). Entende-se por Funções Executivas (FE) "um conjunto de habilidades cognitivas de nível superior, que permitem a orientação e o gerenciamento dos processos cognitivos e comportamentais” (OLIVEIRA; LIMA; COUTO, 2019, p. 31).

Portanto, faz-se necessária uma (re)elaboração das práticas pedagógicas, com ênfase naquelas direcionadas a crianças com TDAH, pois “a utilização de novas tecnologias pode influenciar diretamente no aprendizado de todos os alunos, e é um recurso muito interessante que pode contribuir para uma aprendizagem intensa” (MOURA; SILVA; SILVA, 2019, p. 4), na medida em que podem ser utilizadas para aproximar o educando dos conteúdos escolares ao apresentar recursos atrativos e mais próximos de sua realidade e interesses.

Apresenta-se como possibilidade de intervenção a criação de um livro-jogo, obra que faz com que a narrativa apresentada tenha diversos desfechos a partir das escolhas do jogador. É desenvolvido no 
Software Twine, uma ferramenta de código aberto produzida em 2009 por Chris Klimas, que tem como objetivo possibilitar a criação de narrativas interativas e não-lineares.

Considerando-se os estudos de Sobreira, Nunes e Morassi (2013), levanta-se como hipótese desta investigação que a construção de narrativas não-lineares favorece o desempenho do educando com TDAH, visto que a produção de narrativas permeia todo o currículo do ensino fundamental, projetando a melhoria do nível de leitura e escrita dos discentes. Sobre as narrativas não-lineares, os autores afirmam que a elaboração de tal escrita pode "atrair os leitores infantis e favorecer as possibilidades de tomadas de decisão, a realização de uma leitura não linear própria dos leitores internautas, aliados ao uso da tecnologia” (SOBREIRA; NUNES; MORASSI, 2013, p. 160-161). Para os autores, a redação sob esse molde possibilita que o autor da história idealize diversas linhas narrativas com alguns possíveis desdobramentos, viabilizando o leitor para optar pelo desfecho de sua história de autoria própria.

De acordo com os estudos de Marques e Cordenonsi (2017) ao pesquisar a produção de um jogo de histórias interativas por meio da utilização dos softwares Twine e Storybird em uma escola pública de ensino médio, foi possível observar "a participação e argumentação efetiva e de qualidade de todos os alunos da turma. Essa evidência contribui para a confirmação das potencialidades do uso das TICs, para o direcionamento de uma prática pedagógica capaz de ser atrativa para os alunos.” (MARQUES; CORDENONSI, 2017, p. 5).

Utiliza-se o software de maneira interventiva com a criança que apresenta TDAH para estudar conceitos históricos, partindo de uma segunda hipótese, a de que tais recursos são atrativos ao público e podem ser utilizados a favor do corpo docente das instituições de ensino ao propor conteúdos diversificados de maneira expressiva e significativa. Considera-se que, segundo Fantin (2015), apesar de brincadeiras tradicionais ainda fazerem parte do repertório lúdico das crianças e adolescentes, muitos outros elementos estão sendo agregados nessa cultura em decorrência da mídia, como os jogos eletrônicos e digitais.

Nesse sentido, considerou-se investigar: de que forma o desenvolvimento de um livro-jogo influencia na compreensão que um aluno com TDAH apresenta sobre conceitos históricos?

Considerando-se que "os jogos sempre foram motivadores para estudantes em todo o espectro de habilidades acadêmicas” (LUTTERODT; AUSTIN, 1982, p. 426 apud BANDEIRA, 2009, p. 259), a finalidade deste estudo é descrever o processo de elaboração do livro-jogo pela criança com TDAH ao estudar conceitos históricos.

Para essa finalidade, utiliza-se como método de pesquisa o Estudo de Caso pautado na obra de Yin (2015), a partir de três etapas, com planejamento e coleta de dados específicos e com triangulação metodológica a partir da análise interpretativa dos dados.

\section{TRANSTORNO DE DÉFICIT DE ATENÇÃO E HIPERATIVIDADE NO CONTEXTO DAS TECNOLOGIAS DIGITAIS DA INFORMAÇÃO E COMUNICAÇÃO}

O Manual Diagnóstico e Estatístico de Transtornos Mentais: DSM-5 (APA, 2013, p. 59), define como TDAH "um padrão persistente de desatenção e/ou hiperatividade-impulsividade que interfere no funcionamento e no desenvolvimento", caracterizado por desatenção ou hiperatividade e impulsividade de acordo com os sintomas que o sujeito apresentar nos primeiros seis meses de vida. São critérios diagnósticos do Transtorno do Déficit de Atenção e Hiperatividade:

Um padrão persistente de desatenção e/ou hiperatividade-impulsividade que interfere no funcionamento e no desenvolvimento, conforme caracterizado por (1) e/ou (2):

1. Desatenção: Seis (ou mais) dos seguintes sintomas persistem por pelo menos seis meses em um grau que é inconsistente com o nível do desenvolvimento e têm impacto negativo diretamente nas atividades sociais e acadêmicas/profissionais:

Nota: Os sintomas não são apenas uma manifestação de comportamento opositor, desafio, hostilidade ou dificuldade para compreender tarefas ou instruções. Para adolescentes mais velhos e adultos (17 anos ou mais), pelo menos cinco sintomas são necessários.

a. Frequentemente não presta atenção em detalhes ou comete erros por descuido em tarefas escolares, no trabalho ou durante outras atividades (p. ex., negligência ou deixa passar detalhes, o trabalho é impreciso). 
b. Frequentemente tem dificuldade de manter a atenção em tarefas ou atividades lúdicas (p. ex., dificuldade de manter o foco durante aulas, conversas ou leituras prolongadas).

c. Frequentemente parece não escutar quando alguém lhe dirige a palavra diretamente (p. ex., parece estar com a cabeça longe, mesmo na ausência de qualquer distração óbvia).

d. Frequentemente não segue instruções até o fim e não consegue terminar trabalhos escolares, tarefas ou deveres no local de trabalho (p. ex., começa as tarefas, mas rapidamente perde o foco e facilmente perde o rumo).

e. Frequentemente tem dificuldade para organizar tarefas e atividades (p. ex., dificuldade em gerenciar tarefas sequenciais; dificuldade em manter materiais e objetos pessoais em ordem; trabalho desorganizado e desleixado; mau gerenciamento do tempo; dificuldade em cumprir prazos).

f. Frequentemente evita, não gosta ou reluta em se envolver em tarefas que exijam esforço mental prolongado (p. ex., trabalhos escolares ou lições de casa; para adolescentes mais velhos e adultos, preparo de relatórios, preenchimento de formulários, revisão de trabalhos longos).

g. Frequentemente perde coisas necessárias para tarefas ou atividades (p. ex., materiais escolares, lápis, livros, instrumentos, carteiras, chaves, documentos, óculos, celular).

h. Com frequência é facilmente distraído por estímulos externos (para adolescentes mais velhos e adultos, pode incluir pensamentos não relacionados).

i. Com frequência é esquecido em relação a atividades cotidianas (p. ex., realizar tarefas, obrigações; para adolescentes mais velhos e adultos, retornar ligações, pagar contas, manter horários agendados) (APA, 2013, p. 59).

Considerando-se tais características, é certo que a rotina escolar em seu formato tradicional, com diversas atividades escritas, poucos exemplos concretos e aulas predominantemente expositivas, dificulta a imersão da criança com desatenção nesses espaços. A complexidade em cumprir normas estabelecidas, bem como manter o foco em atividades de longa duração podem gerar situações de desgaste e frustração pela criança que apresenta as características citadas anteriormente, por não conseguir acompanhar os desafios propostos pelo corpo docente. Além disso, é comum observar as relações hierárquicas em contexto escolar, onde normas e contratos de convivência são impostos às crianças e aos adolescentes, sem uma consulta prévia ou debate sobre tais questões, o que agrava o quadro de maneira significativa, tendo em vista que não se trata de uma construção, e sim de sua internalização. Existem ainda casos em que a criança pode apresentar:

2. Hiperatividade e impulsividade: Seis (ou mais) dos seguintes sintomas persistem por pelo menos seis meses em um grau que é inconsistente com o nível do desenvolvimento e têm impacto negativo diretamente nas atividades sociais e acadêmicas/profissionais:

Nota: Os sintomas não são apenas uma manifestação de comportamento opositor, desafio, hostilidade ou dificuldade para compreender tarefas ou instruções. Para adolescentes mais velhos e adultos (17 anos ou mais), pelo menos cinco sintomas são necessários.

a. Frequentemente remexe ou batuca as mãos ou os pés ou se contorce na cadeira.

b. Frequentemente levanta da cadeira em situações em que se espera que permaneça sentado (p. ex., sai do seu lugar em sala de aula, no escritório ou em outro local de trabalho ou em outras situações que exijam que se permaneça em um mesmo lugar).

c. Frequentemente corre ou sobe nas coisas em situações em que isso é inapropriado. (Nota: Em adolescentes ou adultos, pode se limitar a sensações de inquietude.)

d. Com frequência é incapaz de brincar ou se envolver em atividades de lazer calmamente.

e. Com frequência "não para”, agindo como se estivesse "com o motor ligado” (p. ex., não consegue ou se sente desconfortável em ficar parado por muito tempo, como em restaurantes, reuniões; outros podem ver o indivíduo como inquieto ou difícil de acompanhar).

f. Frequentemente fala demais.

g. Frequentemente deixa escapar uma resposta antes que a pergunta tenha sido concluída (p. ex., termina frases dos outros, não consegue aguardar a vez de falar).

h. Frequentemente tem dificuldade para esperar a sua vez (p. ex., aguardar em uma fila). 
i. Frequentemente interrompe ou se intromete (p. ex., mete-se nas conversas, jogos ou atividades; pode começar a usar as coisas de outras pessoas sem pedir ou receber permissão; para adolescentes e adultos, pode intrometer-se em ou assumir o controle sobre o que outros estão fazendo) (APA, 2013, p. 60).

Crianças com hiperatividade possuem um conjunto de características que tornam seu ritmo mais “acelerado" do que o ritmo das demais crianças que compõem o espaço escolar. Saber direcionar estratégias que envolvam o discente nessa condição faz-se essencial para o desenvolvimento pleno da criança. Atividades práticas e dinâmicas que direcionem energias para os processos de ensino e aprendizagem facilitam o desenvolvimento das potencialidades desse público.

Subdividem-se em:

a. Apresentação predominantemente desatenta: identificação dos critérios de desatenção e ausência dos critérios de hiperatividade nos últimos seis (6) meses;

b. Apresentação predominantemente hiperativa/impulsiva: identificação dos critérios de hiperatividade e ausência do preenchimento dos critérios de desatenção nos últimos seis meses;

c. Apresentação combinada: identificação dos critérios de desatenção e hiperatividade nos últimos seis (6) meses.

Ainda segundo o manual (APA, 2013), o TDAH enquadra-se no grupo dos transtornos de neurodesenvolvimento. Manifestam-se em uma fase que, por vezes, antecedem a escolar, e podem impactar as relações sociais, afetivas, acadêmicas ou profissionais, persistindo na vida adulta.

Cabe à instituição escolar planejar adaptações de modo que possa propiciar a inserção e a inclusão desse grupo em ambiente regular, assegurando condições para a permanência e para o seu desenvolvimento global, visto que a aprendizagem "não ocorre simplesmente pela transmissão de informações, mas sim é resultado de um processo de construção interna, a partir de processos de interação com o meio, seja ele, físico, digital virtual e/ou social” (FROSI; SCHLEMMER, 2010, p.115).

Nesse cenário de diversidade nos espaços escolares, a Base Nacional Comum Curricular (BRASIL, 2017, p. 61) estabelece que "ao aproveitar o potencial de comunicação do universo digital, a escola pode instituir novos modos de promover a aprendizagem, a interação e o compartilhamento de significados entre professores e estudantes", facilitando o envolvimento e o protagonismo dos discentes, considerando o engajamento desse público na cultura digital. Nessa perspectiva, Fantin (2015, p. 198) afirma que "crianças de diferentes contextos socioculturais, nas mais adversas condições estão aprendendo a brincar, a ganhar, a perder, a socializar e a se organizar em redes através da cultura digital”.

Os jogos podem trazer um novo panorama ao elo discente/docente, além de dinamizar o processo de construção do conhecimento, conforme estabelecem Grübel e Bez (2006) pois estimulam a criticidade do aluno e a construção de seus saberes a partir de uma postura ativa e investigativa, gerando uma apropriação dos conteúdos apresentados de maneira processual e significativa. O papel do professor é selecionar e orientar essa ligação de maneira proveitosa, possibilitando o alcance do desenvolvimento pleno, considerando que, por meio da brincadeira, a criança "explora o mundo, constrói o seu saber, aprende a respeitar o outro, desenvolve o sentimento de grupo, ativa a imaginação e se auto realiza." (GRUBEL; BEZ, 2006, p.2).

Assim, o livro-jogo emerge como ferramenta de apoio pedagógico ao TDAH no estímulo de habilidades de escrita, delimitação de objetivos, tomadas de decisão, elaboração de estratégias, resolução de testes, dentre outras possibilidades que proporcionam ao aluno uma forma de lidar com suas especificidades de maneira lúdica e estimulante.

O desenvolvimento de um livro-jogo pode acontecer por meio do Twine, uma ferramenta de código aberto que propicia a criação de histórias interativas e não-lineares, com desfecho definido a partir das escolhas dos participantes.

Utilizou-se a ferramenta Twine online em sua versão 2.3.3, com o formato Harlowe (padrão da versão). O recurso possibilita a criação de hipertextos, permitindo que o leitor/jogador possa adicionar elementos e tomar decisões que influenciarão diretamente no desfecho da história. Optou-se por esse formato de narrativa, pois as ramificações que a elaboração do livro-jogo não-linear suscita, demanda 
do desenvolvedor um planejamento prévio para que todos as aberturas realizadas em seu enredo possam ter um desfecho adequado, sempre preocupando-se com a experiência que o usuário terá ao utilizar o material desenvolvido. Além disso, o recurso não demanda conhecimentos prévios sobre linguagem de programação, tornando-se de fácil uso por crianças.

Ao evidenciar conteúdos escolares como justificativa e ressignificação para o desenvolvimento de mídias, "seu uso é favorecido pelo contexto lúdico, oferecendo à criança a oportunidade de utilizar a criatividade, o domínio de si, à afirmação da personalidade, o imprevisível” (OLIVEIRA; SOUZA, 2011, p. 9-10). Dessa forma, considerou-se pertinente investigar a relevância das TDICs em contexto educacional, bem como suas atribuições e contribuições no processo de aprendizagem, considerando a pluralidade de saberes, vivências e interesses.

Com base nos estudos de Oliveira, Lima e Couto (2019) as Funções Executivas desenvolvidas pela criança com TDAH podem ser alteradas, gerando impactos no processo de escolarização. Portanto, crianças que apresentam esse transtorno podem sentir dificuldades em desempenhar tarefas que demandem tomadas de decisão ou elaboração de estratégias para o alcance dos objetivos traçados.

Acredita-se, portanto, que os jogos digitais podem ser utilizados como instrumentos de estimulação se oferecidos por profissionais capacitados que possam mediar esse processo, pois tais recursos implicam no "desenvolvimento das Funções Executivas nas crianças, melhorando seu foco atencional, bem como controle inibitório, memória de trabalho, capacidade de planejamento e flexibilidade cognitiva" (OLIVEIRA; LIMA; COUTO, 2019, p.32).

Considerando-se ainda o que dizem Ramos, Melo e Mattar (2018, p. 675) “a proposição do uso de jogos digitais para o aprimoramento da capacidade de atenção constitui-se como uma intervenção que visa garantir melhores condições de aprendizagem, favorecendo, assim, a inclusão dos alunos”, a motivação, a valorização dos conhecimentos prévios e o tempo de exposição à atividade interferem diretamente no processo de formação dessa habilidade, permitindo que a criança com TDAH possa alcançar um bom nível de desempenho escolar. Por meio de seu potencial, os jogos digitais podem tornar o ensino mais envolvente e significativo, na medida em que o corpo discente se identifica com os recursos utilizados para demonstrar os conteúdos trabalhados. "A partir disso, destaca-se o uso dos jogos digitais por suas características que incluem os desafios, as regras, a narrativa e o feedback para criar experiências de aprendizagem que favoreçam o aprimoramento das habilidades cognitivas.” (RAMOS; MELO; MATTAR, 2018, p. 688).

Percebe-se, então, que o desenvolvimento de um livro-jogo pode vir a despertar na criança com TDAH uma identificação com os conteúdos propostos, considerando o contexto de imersão digital na qual está inserida, além de aprimorar funções executivas que são consideradas afetadas pelo transtorno, como autocontrole, memória de trabalho e flexibilidade cognitiva, habilidades necessárias para um desempenho escolar satisfatório. Além disso, é certo que a diversificação metodológica contempla todos os alunos, sem exceção, e portanto propicia uma quebra com as ferramentas tradicionais de ensino possibilitando a renovação de papéis dentro dessa instituição. Nesta perspectiva, o aluno se coloca no lugar de protagonista na construção dos seu conhecimento teórico/prático e o professor como aquele que faz a mediação ao selecionar recursos, oferecer ferramentas adequadas, provocar debates ou sanar dúvidas, horizontalizando as relações no ambiente escolar.

\section{METODOLOGIA}

Utilizou-se como método de pesquisa o Estudo de Caso. Segundo Yin (2015, p. 17), por meio desta abordagem, o pesquisador "investiga um fenômeno contemporâneo (o caso) em profundidade e em seu contexto de mundo real" sendo pautado em um único caso, pois este "pode ser usado, então, para determinar se as proposições são corretas ou se algum conjunto alternativo de explicações pode ser mais relevante" (YIN, 2015, p. 54).

Foram coletados dados relativos a uma criança com TDAH, com oito (8) anos de idade, matriculada em uma instituição privada de Fortaleza-CE, cursando o $3^{\circ}$ ano do Ensino Fundamental, com encontros realizados às sextas-feiras após o período do almoço. A duração das atividades foi definida de acordo 
com o engajamento e a disponibilidade da criança, visto que geralmente apresenta inquietação quando exposto a atividades longas, com duração média de 40 a 50 minutos. É importante observar que, para a realização das atividades, houve um consentimento dos pais por escrito autorizando a participação da criança no processo investigativo.

Segundo o relatório semestral elaborado pela psicóloga atuante na instituição de ensino pesquisada, em relação a aspectos comportamentais, a criança, que entrou na escola em 2014 no Infantil III apresentava bastante agitação. Após orientações provenientes da própria instituição para a busca de profissionais especializados para a análise do quadro do aluno (neurologista, terapeuta ocupacional, entre outros), em 2016 os pais apresentaram à escola um laudo que o diagnosticou com Transtorno de Déficit de Atenção e Hiperatividade (CID 10 F90). Atualmente, João (nome fictício) ainda apresenta episódios de inquietação, irritabilidade, além de ter dificuldade em ser contrariado.

Em relação aos aspectos cognitivos, segundo a descrição da professora e psicóloga, a criança não acompanha a leitura dos textos propostos, dispersando-se com facilidade. Constantemente vem apresentando sonolência no início da manhã, o que acarreta indisposição e resistência para a realização das atividades propostas.

A pesquisa foi subdividida em três etapas: planejamento, coleta e análise de dados. O planejamento foi iniciado em abril de 2019 com a seleção das ferramentas utilizadas, estudo do software Twine e preparação de material para atividades de sondagem.

A coleta de dados foi desenvolvida em três momentos, cada qual executado a partir de protocolos desenvolvidos na etapa de planejamento compostos pelos seguintes elementos: apresentação dos objetivos gerais do projeto de pesquisa, dos objetivos específicos da coleta, da descrição das atividades desenvolvidas, de questões necessárias para nortear o trabalho no momento da execução das atividades e um guia para a elaboração do relatório do estudo de caso.

O primeiro momento ocorreu no dia 25 de abril de 2019, em que a criança realizou atividades de sondagem. Ressalta-se que a proposta da aplicação dos exercícios é coletar os conhecimentos prévios do discente sobre os conteúdos a serem desenvolvidos posteriormente no livro-jogo. As atividades foram dispostas em formato de jogo para que não causasse exaustão, visto que a criança estaria saindo de seu primeiro turno de aula. Os materiais utilizados nesse primeiro momento foram fichas com imagens de monumentos históricos e suas devidas descrições para que João realizasse a associação entre fotografia e definição, um jogo de tabuleiro para a identificação de estados e capitais, além de mapas e uma folha em branco para que o discente listasse os patrimônios históricos que já conhecia (figura 1).

\section{FIGURA 1: LIVRO-JOGO DESENVOLVIDO POR JOÃONO TWINE}

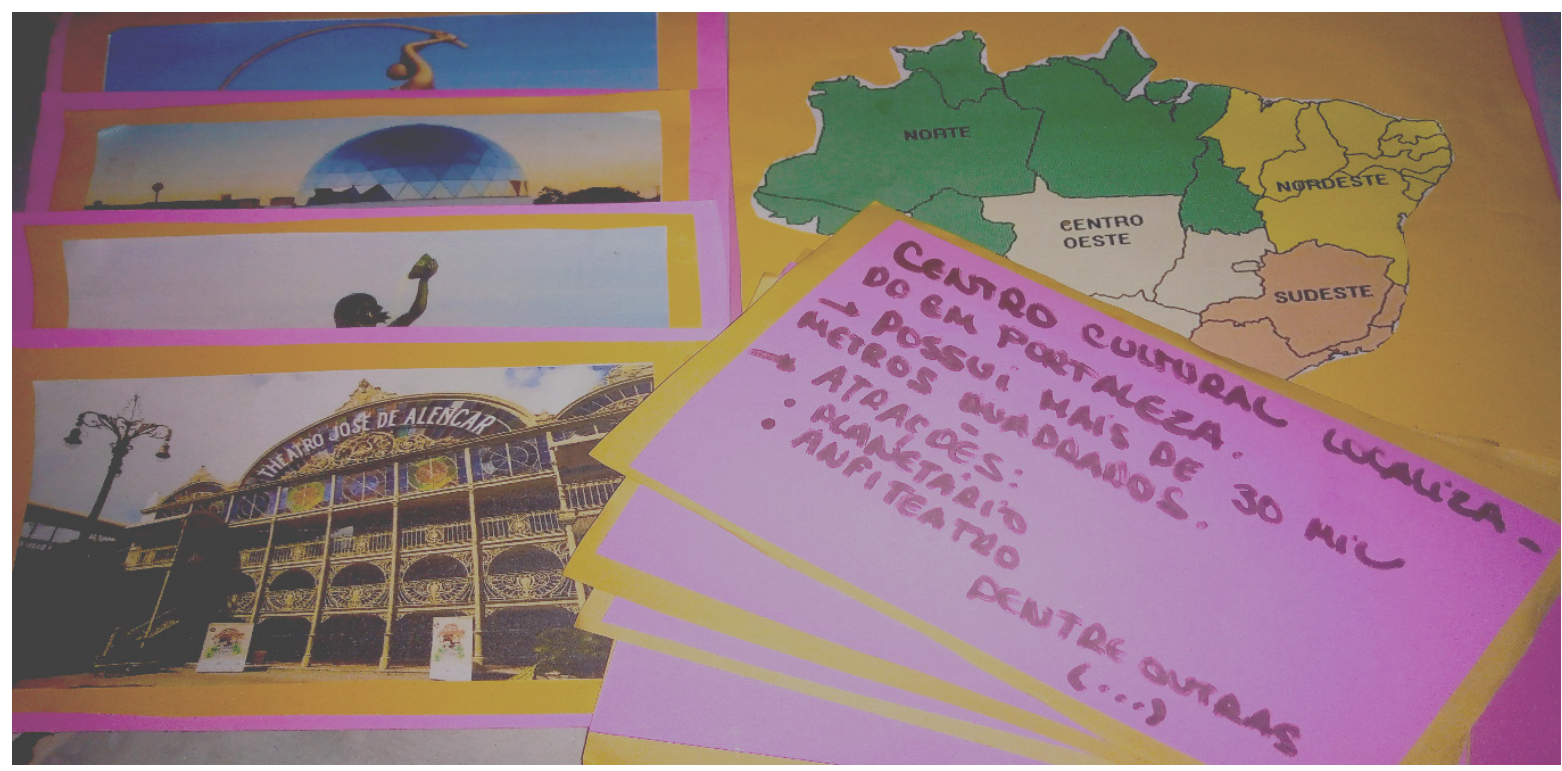

FONTE: REGISTROS DOS AUTORES, 2019 . 
O segundo momento foi desenvolvido no dia 26 de abril de 2019. João requisitou ajuda para a construção de um jogo de tabuleiro sobre a temática estudada. Salienta-se que tal atividade não estava inclusa no planejamento, mas foi atendida e desempenhada de maneira fluida, contando com o total empenho de João. O terceiro momento ocorreu nos dias 30 de abril e 17 de maio de 2019, datas em que o discente observado procedeu com o desenvolvimento do livro-jogo, contando com pequenas intervenções do pesquisador referente aos comandos do software. Foram três os instrumentos de coleta de dados: roteiro de observação das atividades de sondagem, jogo de tabuleiro e livro-jogo desenvolvidos pelo sujeito da pesquisa.

A terceira etapa diz respeito à análise de dados que ocorreu de forma interpretativa por meio da triangulação metodológica de dados vinculados aos três instrumentos utilizados na coleta da pesquisa em desenvolvimento. Foram analisadas as anotações referentes às atividades de sondagem e do jogo de tabuleiro para o levantamento dos conhecimentos prévios do sujeito da pesquisa e comparação entre as relações estabelecidas pela criança ao desenvolver o livro-jogo e as características atitudinais descritas no mais recente relatório semestral de João. A análise de dados se subdivide em dois focos: a relação que a criança estabelece com as TDICs e os impactos no seu comportamento a partir da utilização dessa nova abordagem metodológica.

\section{RESULTADOS E DISCUSSÕES}

Os trabalhos desenvolvidos com João, em todos os momentos da coleta de dados, abordaram a temática "Fortaleza e seus patrimônios históricos", contemplando as unidades temáticas "as pessoas e os grupos que compõem a cidade e o município" e "noção de espaço público e privado", presentes na Base Nacional Comum Curricular (BRASIL, 2017, p. 410), apresentando desafios que estimulam a investigação acerca da identificação dos patrimônios históricos e culturais de sua cidade ou região, além de discutir as razões culturais, sociais e políticas, registros de memória na cidade (nomes de ruas, monumentos, edifícios, entre outros), critérios que explicam a escolha desses nomes, o mapeamento dos espaços públicos e a identificação de suas funções, as diferenças entre o espaço doméstico, os espaços públicos e as áreas de conservação ambiental, habilidades almejadas pela diretriz.

Considerando-se tal contexto, os dados foram coletados a partir de atividades intrínsecas à temática escolhida e organizados em três sessões para melhor compreensão e análise. Na etapa inicial da pesquisa foram elaboradas duas atividades de sondagem apresentando como base a temática escolhida para o desenvolvimento do livro-jogo, de forma lúdica para o levantamento dos conhecimentos prévios de João, além de possibilitar uma aproximação entre pesquisador e sujeito de pesquisa.

Foram disponibilizados três mapas para a verificação do nível da linguagem cartográfica, cartões com imagens de alguns patrimônios históricos e sua descrição, com o objetivo de verificar a leitura iconográfica e a análise cultural ao associar imagem e história, além de uma ficha em branco para que a criança listasse livremente aqueles que já conhece, competências esperadas para a área de Ciências Humanas para o Ensino Fundamental (BRASIL, 2017).

No segundo momento, foram concedidos cartolina em branco, lápis de cor, giz de cera e canetinhas para a elaboração do jogo de tabuleiro. A criança desenhou livremente alguns monumentos históricos, como estátua de Iracema e o prédio do Centro de Arte e Cultura Dragão do Mar, além de uma trilha que interliga todas as ilustrações. Ao ser questionada, a criança deu instruções sobre as regras do desafio: o jogador lança o dado, que indicará o número de casas que ele deverá avançar; se parar em uma casa vazia, o jogador pode seguir sem interrupções; caso pare em um dos monumentos, o jogador precisará acertar o seu nome; em caso de erro, perde sua vez de jogar por uma rodada.

No que diz respeito à relação que a criança estabelece com as tecnologias digitais observou-se interesse por parte do aluno pela temática estudada, uma vez que respondeu bem a todos os jogos e demais atividades propostas, exceto por aquela que demanda um esforço maior na escrita (atividade da ficha). Neste caso, João demonstrou ansiedade para a conclusão, além de não registrar na escrita os detalhes de informações que compartilhava verbalmente. Segundo Gonçalves-Guedim et al. (2017, p. 243) "crianças diagnosticadas com TDAH apresentam maior dificuldade no aprendizado por influência de alterações 
expressivas de linguagem e/ou por transtornos na apropriação da escrita, quadros que podem resultar em prejuízos ao desempenho escolar”.

Quando solicitado a registrar por escrito todos os patrimônios históricos citados ao longo das atividades com o intuito de retomar esses mesmos bens posteriormente na elaboração do livro-jogo, João listou apenas três, apesar de ter verbalizado, em média, o dobro de obras.

Em relação aos impactos das atividades de sondagem sobre o comportamento da criança, é possível perceber que João demonstrou um bom desenvolvimento nas competências específicas de Geografia para o Ensino Fundamental de acordo com as diretrizes apresentadas na BNCC (BRASIL, 2017) ao revelar um pensamento espacial adequado ao desenvolvimento cognitivo da idade, realizando leituras cartográficas, iconográficas e extração das informações, além de apresentar em sua fala o princípio de localização.

De acordo com o relatório pedagógico fornecido pela instituição, João demonstra resistência na execução de atividades propostas, além de fácil dispersão. No entanto, mesmo sendo submetido a um número significativo de exercícios, permaneceu focado na maior parte das atividades de sondagem e não apresentou sinais de irritabilidade. $\mathrm{O}$ alcance das competências estabelecidas pelo documento supracitado demonstra ainda que o sujeito teve um desempenho satisfatório nos jogos analógicos. Entretanto, ainda demonstrou resistência na proposta que se aproximava dos recursos tradicionais de ensino (ficha para escrita). Segundo Jenkins (2009, p. 30) “em vez de falar sobre produtores e consumidores de mídia como ocupantes de papéis separados, podemos agora considerá-los como participantes interagindo de acordo com um novo conjunto de regras, que nenhum de nós entende por completo”. Partindo desse princípio, compreende-se que, no que diz respeito a recursos que situam o aluno com TDAH em uma posição passiva, há um distanciamento do interesse do aluno e em sua disposição para executar os desafios propostos.

Considerando-se as características que crianças com TDAH podem apresentar, bem como os impactos causados nas relações de ensino-aprendizagem, é importante ressaltar a importância das adaptações metodológicas na inclusão escolar do aluno com esse transtorno. Aproximar os conteúdos da realidade daqueles que convivem com o déficit de atenção e hiperatividade pode tornar o processo de construção dos conhecimentos mais efetivo.

No que diz respeito ao desenvolvimento do livro-jogo, João optou por produzir seu material em formato de quiz com perguntas e respostas relacionadas a conhecimentos históricos e geográficos dos patrimônios localizados na cidade de Fortaleza - CE. Deste modo, o jogo foi composto por 3 (três) perguntas de múltipla escolha, com 4 (quatro) opções de alternativas cada, além de mensagens de felicitações ou correções direcionadas ao jogador a depender de sua escolha, todas elaboradas pela criança, sem consulta a materiais adicionais.

No que diz respeito à relação que a criança estabelece com as TDICs, a criança evidenciou seu interesse ao não apresentar incômodo ou dispersão ao digitar longos comandos de texto no decorrer de sua produção. Essa constatação diverge dos dados encontrados na documentação pedagógica de João que foi construída a partir dos relatos do docente atuante e suas observações sobre a rotina escolar, e que apontam déficits nas habilidades de leitura e escrita. Diverge, ainda, da atividade de sondagem que solicitava da criança uma listagem dos patrimônios históricos que conhecia. O comportamento de João pode ser explicado com base nos estudos de Rocha, Alves e Nery (2014, p. 75) que afirmam que os "jogos que desenvolvem as funções executivas poderiam, desta forma, configurarem-se como recurso complementar no tratamento multimodal para o TDAH, associando ao treinamento das funções, maior engajamento, motivação e aprendizado intrínseco".

João, em nenhum momento, solicitou ajuda para a criação das perguntas. A criança verbalizava as questões formuladas antes de digitar, como meio de organizar seus pensamentos. Assim, imediatamente, transcrevia no software, sem que os envolvidos na pesquisa necessitassem repetir algum dos comandos já apresentados, demonstrando atenção e memorização contínua (figuras 2 e 3). 
FIGURA 2: LIVRO-JOGO DESENVOLVIDO POR JOÃO NO TWINE

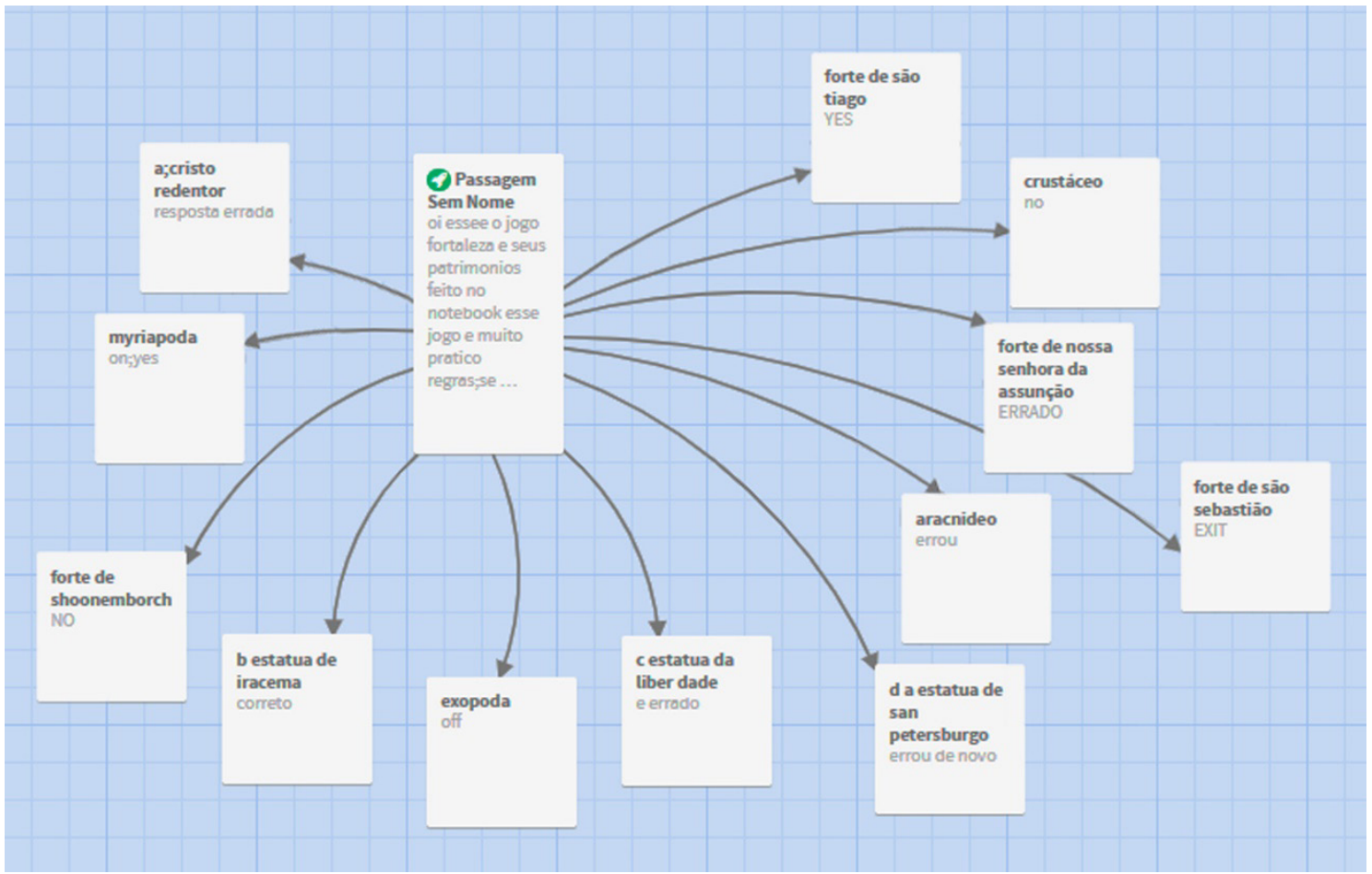

FONTE: REGISTROS DOS AUTORES, 2019

FIGURA 3: TELA DO LIVRO-JOGO DESENVOLVIDA POR JOÃO

oi essee o jogo fortaleza e seus patrimonios feito no notebook

esse jogo e muito pratico

regras;se voce fazer uma pergunta ; faça a resposta exenplo qual e a fruta

que e usada na feijoada a jabuticaba; b; laranja;c morango ou ; d goiaba

\section{PERGUNTA 1}

qual e a estatua da beira mar?

a;cristo redentor

b estatua de iracema

c estatua da liber dade

d a estatua de san petersburgo

fortaleza,memória viva

PERGUNTA 2

qual é o primeiro forte a ser construído ?

forte de shoonemborch

forte de são sebastião

forte de são tiago

forte de nossa senhora da assunção

FONTE: REGISTROS DOS AUTORES, 2019

Em relação aos impactos no seu comportamento a partir da utilização dessa nova abordagem metodológica, a criança demonstrava interesse e envolvimento em todo o tempo disposto para a execução do exercício proposto, finalizando apenas com a demanda do cumprimento de outra atividade integrada à 
sua rotina escolar. Os fatos destacados ressaltam a importância do direcionamento de um trabalho escolar que valorize "interesses manifestos pelas crianças" (BRASIL, 2017, p. 58).

Ao tornar a apresentação dos conteúdos atrativa e carregada de significados é possível trazer a criança para o centro do processo de aprendizagem, estimular sua autonomia, bem como facilitar sua compreensão acerca das temáticas propostas. A partir do momento que sua essência se mescla ao conglomerado de conteúdos, pode finalmente se identificar como parte significativa de um todo. "A responsabilidade da aprendizagem agora é do estudante, que tem que assumir uma postura mais participativa, na qual resolve problemas, desenvolve projetos e, com isto, cria oportunidades para a construção de seu conhecimento" (VALENTE, 2019, p. 112).

Apesar de assegurado legalmente, a inserção das TDICs em um contexto escolar nem sempre é considerada uma atividade simples. Por vezes, o corpo docente disputa atenção com os diversos recursos tecnológicos que acompanham cotidianamente a rotina dos discentes. Isso provém de uma compreensão tradicional de ensino, que considera o professor o centro de todo o processo e enfatiza o ensino expositivo em detrimento da aprendizagem. Essa centralização dificulta o desenvolvimento da autonomia e a participação das crianças na construção dos saberes escolares, o que a distancia de uma trajetória educativa satisfatória e significativa. De acordo com Frosi e Schlemmer (2010), o desinteresse no ambiente escolar está diretamente vinculado com as relações ali estabelecidas. Portanto, a aprendizagem deixa de ser prazerosa na medida que o espaço de trocas representa um local monótono.

Contudo, não se pode fugir da presença dos recursos tecnológicos. Considerar a amplitude de tais meios e a gama de possibilidades que podem ofertar na construção da prática pedagógica fortalece o elo discente/docente ao firmar relações de parcerias e cooperação nesse contexto, considerando que todos os envolvidos na dinâmica escolar são seres competentes e capazes de aprender e ensinar algo novo. Nesse sistema, "o professor passa a ser mais efetivo como guia, como consultor, como desafiador do aluno, auxiliando-o a navegar nesse mar de informação e de recursos digitais, em vez de ser o transmissor de informação" (VALENTE, 2019, p. 99-100).

Ao extinguir as relações hierárquicas presentes nessa instituição, é possível estabelecer momentos de escuta para compreender os interesses e as aflições do corpo discente, dinamizar o ensino tornando os conteúdos apresentados cada vez mais próximos da realidade das crianças, além de propiciar um ambiente onde os saberes são valorizados e trocados a todo instante. Considera-se que tal demanda é essencial para o alcance das competências estabelecidas pela BNCC para a Educação Básica, "valorizar e utilizar os conhecimentos historicamente construídos sobre o mundo físico, social, cultural e digital para entender e explicar a realidade” (BRASIL, 2017, p. 9). Não se trata, portanto, de terceirizar o papel do educador, mas de selecionar ferramentas que enriqueçam as experiências cognitivas.

Quando consultado sobre sua opinião em relação à atividade, a criança afirmou ter gostado e que "poderia usar computador, tablet e celular pra pesquisar na aula" (JOÃO), o que reafirma nesse caso, parâmetros estabelecidos para a Educação Básica de inserção das TDICs no cotidiano escolar, já citado anteriormente. Além disso, demonstra o interesse que o educando possui em tais recursos e, portanto, a possibilidade de maior permanência em uma mesma atividade, excluindo as possíveis barreiras educacionais encontradas durante o processo de ensino e aprendizagem.

Segundo Valente (2019, p. 99), “a aula expositiva deixou de ser importante uma vez que o aluno consegue acessar essa mesma informação de modo mais interessante e, inclusive, com mais detalhes e uso de recursos visuais que facilitam sua compreensão", caracterizando assim as TDICs como meio essencial para a prática pedagógica cotidiana, levando em consideração a onda digital em que os educandos estão sendo imersos de maneira cada vez mais precoce.

Durante a elaboração do jogo, João demonstrou facilidade ao manusear o equipamento e software proposto, o que afirma aquilo que é proposto pela BNCC (BRASIL, 2017, p. 61), ao afirmar que os jovens "têm se engajado cada vez mais como protagonistas da cultura digital, envolvendo-se diretamente em novas formas de interação multimidiática e multimodal e de atuação social em rede”. Segundo o documento, o aluno inserido nessa cultura não assume apenas o papel de consumidor, mas de protagonista dessa nova rede de comunicação. 
Assim, considera-se pertinente problematizar os recursos educacionais oferecidos ao aluno com TDAH no contexto escolar, compreendendo que atividades moldadas sob uma ótica de reprodução e memorização, tornam o ensino fragmentado e abstrato, interferindo em seu rendimento escolar, além de servir como gatilho para comportamentos impulsivos ou até mesmo aumentar o índice de evasão, considerando as relações hierárquicas presentes na sala de aula e como as crianças encontram-se moldadas para atingir um padrão de competência.

O Estatuto da Criança e do Adolescente (ECA) (BRASIL, 1990, p. 46) prevê em seu artigo 53 "igualdade de condições para o acesso e permanência na escola” refutando, em esfera legal, a exclusão de qualquer indivíduo nesse sistema. Apesar disso, é comum que sejam padronizadas as ferramentas e as práticas direcionadas às crianças que estão no nível de desenvolvimento global esperado para sua faixa etária, inserindo, mas não contemplando a diversidade e as especificidades dos discentes. $\mathrm{O}$ fato impossibilita "o pleno desenvolvimento de sua pessoa, preparo para o exercício da cidadania e qualificação para o trabalho” (BRASIL, 1990, p. 46).

No que se refere à influência que a elaboração do livro-jogo na compreensão que uma criança com TDAH apresenta sobre conceitos históricos, observou-se que ela demonstrou um vasto conhecimento sobre a temática, o que seria fruto de seus estudos extracurriculares, sob a orientação de sua mãe. Também constata-se que a elaboração do jogo possibilitou maior imersão no tema, incitando a criatividade do aluno ao elaborar as perguntas de acordo com seus conhecimentos prévios, bem como sua valorização, permitindo que se sentisse mais satisfeita e segura ao estudar a temática.

Além disso, notou-se que João, em todo o processo, manteve-se focado, envolvido na atividade, além de demonstrar autonomia na experimentação de comandos antes desconhecidos por ele. Todo o processo de coleta de dados ocorreu de maneira fluida. Os entraves encontrados condiziam com o cuidado para não ocasionar grandes alterações na rotina da criança.

Em relação a questões atitudinais, João se mostrou receptivo e disposto a interagir. Ao receber o convite para participar da atividade, aceitou prontamente, trazendo diversos questionamentos sobre como e porque essa atividade seria realizada. Após estar ciente de todos os objetivos e procedimentos a serem desenvolvidos, João dedicou-se a todas as fases, desde a sondagem até a finalização do jogo. No decorrer da pesquisa, a criança era pontualmente questionada sobre seu bem-estar, se gostaria de parar ou permanecer em tal atividade. A resposta sempre foi positiva em relação à continuidade das ações, portanto, o livro-jogo foi desenvolvido sem qualquer interrupção.

Não foram registradas nenhuma crise ou comportamento agressivo no decorrer da pesquisa. A criança demonstrou bastante paciência ao compreender e executar os comandos do software, programando suas ramificações de maneira linear, seguindo as orientações fornecidas pelo pesquisador. Mesmo que realizadas em dias diferentes, João demonstrou domínio acerca dos comandos a serem executados, além de situar-se bem em seu roteiro de jogo, retomando com facilidade seu trabalho anterior, como demonstrado na figura 4. 


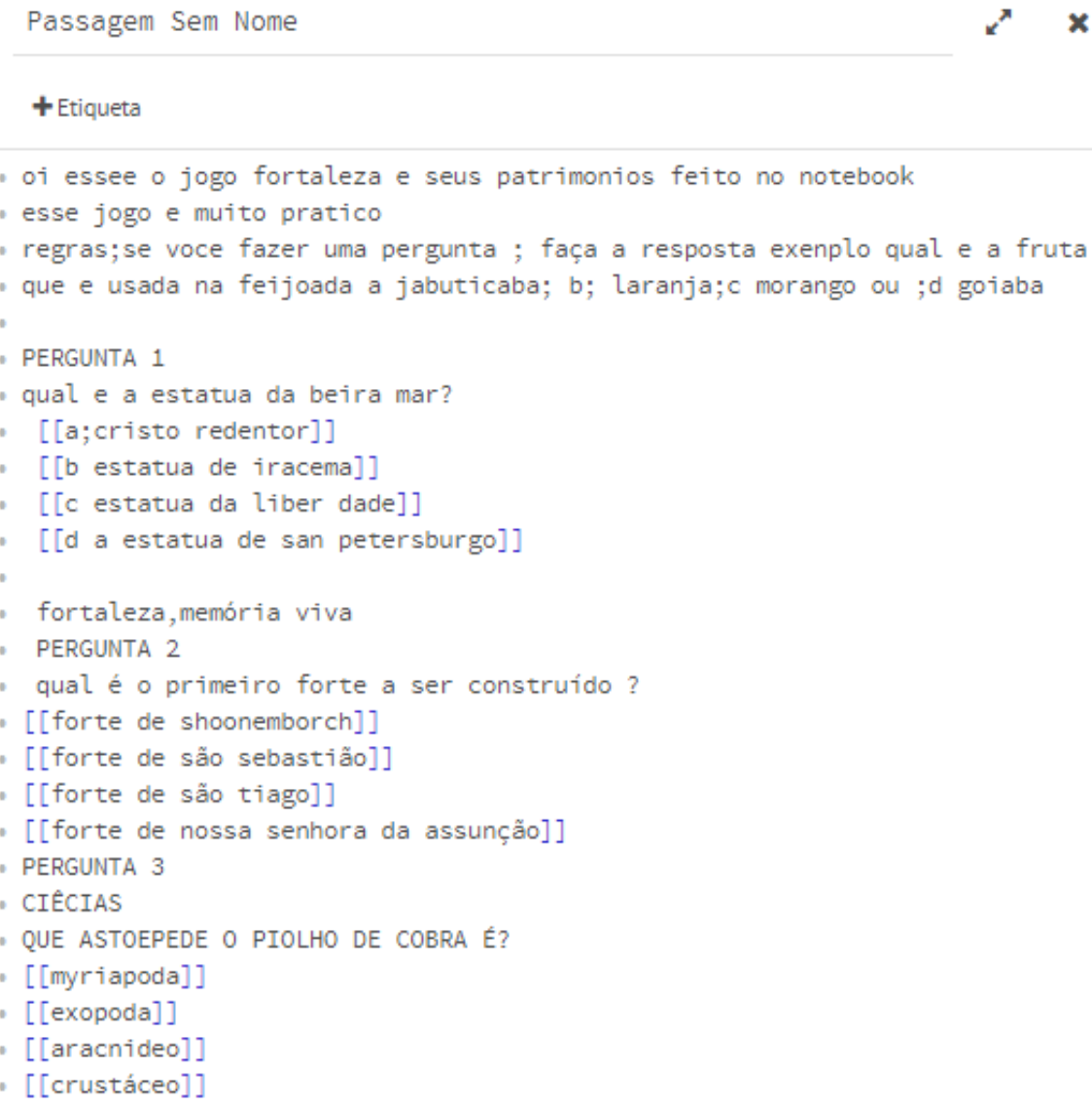

Ao comparar os dados obtidos através das atividades de sondagem e o desempenho da criança ao elaborar o livro-jogo, é possível notar que João teve um bom engajamento no desenvolvimento de ambas as atividades: na elaboração do jogo analógico (jogo de tabuleiro) e no digital (livro-jogo), direcionou sua atenção para a criação do roteiro, a elaboração de regras, demonstrando autonomia durante o delineamento de ambos.

No entanto, no que diz respeito aos aspectos comportamentais observados durante a pesquisa, é possível notar uma disparidade na relação que João estabelece com a escrita ao utilizar recursos tradicionais (ficha para escrita) e Tecnologias Digitais (Twine). No primeiro caso a criança demonstrou cansaço e desinteresse, já ao utilizar o livro-jogo como suporte para a escrita, João demonstrou mais disposição para a realização da atividade. Durante as duas ocasiões de coleta de dados, João mostrou-se paciente e empolgado, e ao se deparar com uma atividade na qual não despertava seu interesse, a criança apenas solicitou a mudança de atividades, sem demonstrar nenhum tipo de comportamento agressivo.

Percebeu-se ainda a satisfação que a criança teve ao jogar seu próprio livro-jogo. A criança simulava surpresa ao escolher as alternativas, além de experimentar todas elas, lendo com bastante empolgação as mensagens impressas em tela. Além disso, João solicitou que fosse feita uma gravação dele apresentando seu próprio recurso, e que, posteriormente, esse material fosse enviado para a mãe para que pudesse jogar também.

Esse aspecto corrobora a ideia de Papert (2008) sobre a necessidade do desenvolvimento de um produto digital por crianças, durante a construção do conhecimento, que possa ser mostrado, avaliado e admirado por outras crianças, jovens ou adultos. Esse momento, para o autor, é importante para a 
consolidação do conhecimento de sua estrutura cognitiva, no sentido de que as pessoas percebam erros e acertos que podem ser repensados com a finalidade de promover a reflexão crítica por parte da criança em diferentes níveis: concreto, abstrato e emocional.

\section{CONSIDERAÇÕES FINAIS}

A partir do desenvolvimento da pesquisa que teve como objetivo descrever o processo de elaboração do livro-jogo por uma criança de oito anos com TDAH ao estudar conceitos históricos, foi possível constatar mudanças significativas no modo como a criança interage com diferentes recursos educacionais.

Em relação à sondagem inicial notou-se amplo conhecimento sobre o conteúdo trabalhado e uma disponibilidade para a elaboração de jogos, demonstrando uma receptividade, oriunda da criança, para o estudo de conteúdos históricos de maneira mais lúdica e construtiva. Entretanto, mesmo que apresentada de maneira contextualizada (dando continuidade aos jogos), a criança demonstrou recusa à escrita presente no exercício de listagem dos conteúdos históricos.

Em relação aos impactos no seu comportamento a partir da utilização dessa nova abordagem metodológica, considera-se importante ressaltar que em um segundo momento a escrita foi encarada de maneira fluida, sendo exercitada sem resistência ou queixas, gerando assim a visualização de elementos que sinalizaram para uma possibilidade de mudança em contexto escolar.

Portanto, compreende-se que a relação que a criança estabelece com as TDICs é satisfatória, e corrobora em uma postura ativa, considerando que ao utilizar tais recursos João conseguiu realizar a escrita de longos textos sem interrupções ou irritabilidade, amenizando as barreiras educacionais apontadas por seus professores.

Nesse sentido, percebeu-se uma conexão entre os resultados obtidos em ambas as fases da pesquisa (sondagem e desenvolvimento do livro-jogo) e o que estabelece a BNCC (BRASIL, 2017) que define, em esfera nacional, as habilidades que cada criança deve desenvolver na Educação Básica. Assim, constata-se que as crianças, inseridas em contexto digital, necessitam de ferramentas que tornem o ensino tão atrativo quanto suas vivências em outros ambientes, além da convicção de que são o centro de sua própria aprendizagem. Para concretizá-la, precisam direcionar energias e esforços na realização de atividades, além de assumir uma postura ativa de investigador dos fenômenos vivenciados ou apresentados. O suporte que as TDICs oferecem nessa etapa mostra-se fundamental para a efetivação da aprendizagem, visto que fazem parte da rotina e do grupo de interesses dos discentes.

Desse modo, considera-se essencial a quebra de uma passividade do aluno em seu processo de aquisição de saberes, que inviabiliza a imersão da criança nas atividades propostas. No presente caso com a ênfase no aluno com TDAH e sua série de especificidades que tornam esse quadro ainda mais alarmante.

Considerando-se os dados obtidos, pretende-se dar seguimento à presente pesquisa ampliando o grupo de trabalho e estendendo o período de desenvolvimento das atividades, de modo que seja possível ampliar o contato de crianças que apresentam TDAH com softwares que possibilitem a construção do conhecimento e portanto, fazer destes, um caminho para a aprendizagem efetiva e a inclusão social.

\section{REFEREENCIAS}

AMERICAN PSYCHIATRIC ASSOCIATION. Manual diagnóstico e estatístico de transtornos mentais (DSM-5). 5a ed. Porto Alegre: Artmed, 2013.

BRASIL. Base Nacional Comum Curricular. Brasília, DF, 2017.

BRASIL. Constituição da República Federativa do Brasil. Brasília, DF: Senado Federal, 1988.

BRASIL. Estatuto da Criança e do Adolescente. Brasília, DF, 1990.

BANDEIRA, D. Materiais Didáticos. Curitiba, PR: IESDE, 2009. 
FANTIN, M. Crianças e games na escola: entre paisagens e práticas. Revista Latinoamericana de Ciencias Sociales, Niñez y Juventud, v.13, n.1, p. 195-208, Jan./Jun. 2015.

FROSI, F. O; SCHLEMMER, E. Jogos Digitais no Contexto Escolar: desafios e possibilidades para a Prática Docente. In: IX Simpósio Brasileiro de Jogos e Entretenimento Digital (SBGames), 2010, Florianópolis, Anais do IX Simpósio Brasileiro de Jogos e Entretenimento Digital (SBGames), Florianópolis, nov. 2010, p. 115 - 122.

GONCALVES-GUEDIM, T. F.; CAPELATTO, I. V.; AZONI, C. A. S.; CIASCA, S. M.; CRENITTE, P. A. P. Desempenho do processamento fonológico, leitura e escrita em escolares com transtorno de déficit de atenção e hiperatividade. Rev. CEFAC [online], v.19, n.2, p.242-252, 2017. Disponível em: http:// www.scielo.br/scielo.php?pid=S1516-18462017000200242\&script=sci_abstract\&tlng=pt. Acesso em: 17 mai. 2019.

GRUBEL, J. M.; BEZ, M. R. Jogos Educativos. RENOTE - Revista Novas Tecnologias na Educação, v. 4, n. 2, p. 1-7, 2006. Disponível em: https://seer.ufrgs.br/renote/article/view/14270/8183. Acesso em: maio 2019.

JENKINS, H. Cultura da convergência. São Paulo: Aleph, 2009.

MAIA, M. I. R.; CONFORTIN, H. TDAH e aprendizagem: um desafio para a educação. Revista Perspectiva, v. 39, n.148, p. 73-84, dez. 2015

MARQUES, M. P.; CONDENONSI, A. Z. Histórias Interativas para a Disciplina de História no Ensino Médio: Uma Abordagem de Autoria Compartilhada. Novas Tecnologias na Educação, v.15, n.2, p. 1-10, 2017.

MOURA, L. T.; SILVA, K. P. M. O Transtorno de Déficit de Atenção e Hiperatividade (TDAH) e as práticas pedagógicas em sala de aula. Revista Eletrônica Acervo Saúde, n. 22, p. 1-7, 2019.

OLIVEIRA, O. N.; SOUZA, K. R. Jogos digitais: motivação para a aprendizagem contemporânea. In: V SIMPÓSIO NACIONAL ABCIBER, 5., 2011, Florianópolis, SC, Anais do V Simpósio Nacional da ABCiber, Florianópolis: Universidade Federal de Santa Catarina, 2011, p. 1-14.

OLIVEIRA, K. S.; LIMA, C. S.; COUTO, F. P. Jogos Digitais e Funções Executivas em Escolares com Transtorno do Déficit de Atenção e Hiperatividade (TDAH): Algumas Reflexões. Revista Cenas Educacionais, v. 2, n. 1, p. 29-43, 2019.

PAPERT, S. A Máquina das Crianças. Porto Alegre: Artmed, 2008.

RAMOS, D. K.; MELO, H. M.; MATTAR, J. Jogos digitais na escola e inclusão digital: intervenções para o aprimoramento da atenção e das condições de aprendizagem. Revista Diálogo Educacional, v. 18, n. 58, p. 670-692, 2018.

ROCHA, P.; ALVES, L.; NERY, J. Jogos digitais e reabilitação neuropsicológica: delineando novas mídias. In: ANAIS DO I SEMINÁRIO TECNOLOGIAS APLICADA A EDUCAÇÃO E SAÚDE. Salvador, 2014, p. 70-84.

SOBREIRA, E. S. R.; NUNES, M. C.; MORASSI, S. B. Produzindo histórias não lineares: um incentivo à produção escrita e leitura, através do uso contextualizado da tecnologia. In: ANAIS DO XIX WORKSHOP DE INFORMÁTICA NA ESCOLA. São Paulo, 2013, p.160-168.

TOURINHO, A.; BONFIM, C.; ALVES, L. Games, TDAH e Funções Executivas: Uma Revisão da Literatura. In: ANAIS DO XV SIMPÓSIO BRASILEIRO DE JOGOS E ENTRETERIMENTO DIGITAL (SBGAMES), São Paulo, 2016, p. 873-879.

VALENTE, J. A. Tecnologias e Educação a Distância no Ensino Superior: Uso de Metodologias Ativas na Graduação. Trabalho \& Educação, v. 28, n.1, p. 97-113, 2019.

YIN, R. K. Estudo de Caso: Planejamentos e Métodos. Porto Alegre: Bookman, 2015. 